
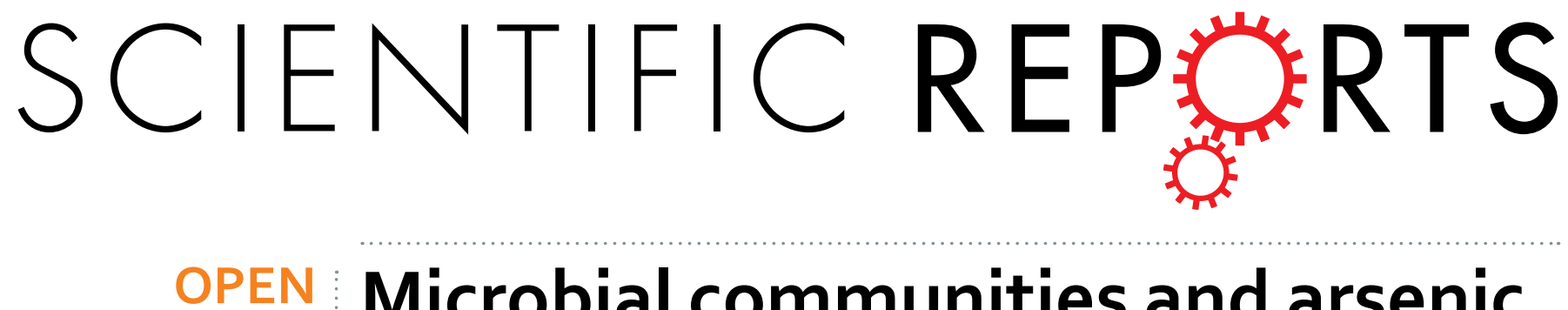

\title{
Microbial communities and arsenic biogeochemistry at the outflow of an alkaline sulfide-rich hot spring
}

Received: 06 October 2015

Accepted: 21 March 2016

Published: 29 April 2016
Zhou Jiang ${ }^{1,2}$, Ping $\mathrm{Li}^{1}$, Joy D. Van Nostrand ${ }^{3}$, Ping Zhang ${ }^{3}$, Jizhong Zhou ${ }^{3,4,5}$, Yanhong Wang ${ }^{1}$, Xinyue Dai ${ }^{1,2}$, Rui Zhang ${ }^{1}$, Dawei Jiang ${ }^{1}$ \& Yanxin Wang ${ }^{1,2}$

Alkaline sulfide-rich hot springs provide a unique environment for microbial community and arsenic (As) biogeochemistry. In this study, a representative alkaline sulfide-rich hot spring, Zimeiquan in the Tengchong geothermal area, was chosen to study arsenic geochemistry and microbial community using Illumina MiSeq sequencing. Over 0.26 million $16 \mathrm{~S}$ rRNA sequence reads were obtained from 5 -paired parallel water and sediment samples along the hot spring's outflow channel. High ratios of $\mathrm{As}(\mathrm{V}) /$ $\mathrm{As}_{\text {sum }}$ (total combined arsenate and arsenite concentrations) (0.59-0.78), coupled with high sulfide (up to $5.87 \mathrm{mg} / \mathrm{L}$ ), were present in the hot spring's pools, which suggested As(III) oxidation occurred. Along the outflow channel, $\mathrm{As}_{\text {sum }}$ increased from 5.45 to $13.86 \mu \mathrm{mol} / \mathrm{L}$, and the combined sulfide and sulfate concentrations increased from 292.02 to $364.28 \mu \mathrm{mol} / \mathrm{L}$. These increases were primarily attributed to thioarsenic transformation. Temperature, sulfide, As and dissolved oxygen significantly shaped the microbial communities between not only the pools and downstream samples, but also water and sediment samples. Results implied that the upstream Thermocrinis was responsible for the transformation of thioarsenic to As(III) and the downstream Thermus contributed to derived As(III) oxidation. This study improves our understanding of microbially-mediated As transformation in alkaline sulfide-rich hot springs.

Hot springs provide a unique environment for examining the evolution of microbial communities in response to geochemistry as these environments harbor versatile microorganisms involved in various metabolic processes for hydrogen gas $\left(\mathrm{H}_{2}\right)$, sulfur $(\mathrm{S})$, iron $(\mathrm{Fe})$ and arsenic $(\mathrm{As})$, as well as having high temperature and a wide range of $\mathrm{pH}_{\text {values }}{ }^{1-5}$. Arsenic biogeochemistry has been studied extensively in acidic hot springs and it is well-documented that high concentrations of sulfide can inhibit microbial As(III) oxidation in acidic springs by inactivating expressed As(III) oxidase (AioA) in microorganisms such as Hydrogenobacter ${ }^{6}$, Hydrogenobaculum ${ }^{7}$ and Acidicaldus ${ }^{8}$. In contrast, sulfide has been shown to enhance microbial As(III) oxidation in the alkaline Mono Lake water by stimulating growth of sulfur-oxidizing bacteria, the first demonstration of the different roles of sulfide on microbial As(III) oxidation in acidic and alkaline environments 9 . Previous studies have revealed the presence of thioarsenic in alkaline sulfidic geothermal waters, and As and S oxidations were closely correlated in this type of system ${ }^{10,11}$. Thioarsenate was identified as the dominant As species at the source of the alkaline sulfide-rich hot springs in Yellowstone National Park (YNP) and account for up to $89 \%$ of total As ${ }^{10,11}$. Upon discharge, thioarsenate is biologically transformed to As(III) along the outflow channels, and is followed by appearance of $\mathrm{As}(\mathrm{V})$ and sulfate as the final products ${ }^{12,13}$. Studies of microbially controlled As transformation in mats or sediments in these alkaline sulfide-rich hot springs have been investigated using enrichments, pure cultures, clone libraries and metagenome sequencing and found Thermocrinis, Thermus and Ectothiorhodospira to be likely involved in transformation of As species ${ }^{14-17}$. As an example, anoxic cultures from alkaline Mono Lake and Big Soda Lake, which were dominated by Ectothiorhodospira, were able to use monothioarsenate as the sole electron donor for anoxygenic photosynthesis ${ }^{16}$. Further, the hyperthermophilic Thermocrinis rubber isolated from

${ }^{1}$ State Key Laboratory of Biogeology and Environmental Geology, China University of Geosciences, Wuhan, 430074, China. ${ }^{2}$ School of Environmental Studies, China University of Geosciences, Wuhan, 430074, China. ${ }^{3}$ Institute for Environmental Genomics and Department of Microbiology and Plant Biology, University of Oklahoma, Norman, OK, 73019, USA. ${ }^{4}$ Earth Sciences Division, Lawrence Berkeley National Laboratory, Berkeley, CA, 94720, USA. ${ }^{5}$ School of Environment, Tsinghua University, Beijing, 100084, China. Correspondence and requests for materials should be addressed to P.L. (email: pli@cug.edu.cn) or Y.W. (email: yx.wang@cug.edu.cn) 


\begin{tabular}{|c|c|c|c|c|c|c|c|c|c|c|c|c|c|c|c|c|}
\hline \multirow{3}{*}{$\begin{array}{l}\text { Distance from } \\
\text { discharge }(\mathrm{m})\end{array}$} & \multicolumn{13}{|c|}{ Aqueous phase } & \multicolumn{3}{|c|}{ Solid phase } \\
\hline & \multirow[b]{2}{*}{$\mathrm{T}^{\circ} \mathrm{C}$} & \multirow[b]{2}{*}{$\mathrm{pH}$} & \multicolumn{2}{|c|}{$\mathrm{mg} / \mathrm{L}$} & \multicolumn{8}{|c|}{$\mu \mathrm{mol} / \mathrm{L}$} & \multirow[b]{2}{*}{$\mathbf{A s}(\mathbf{V}) / \mathbf{A s}_{\text {Sum }}$} & \multicolumn{2}{|c|}{$\mathrm{mg} / \mathrm{kg}$} & \multirow[b]{2}{*}{ TOC(\%) } \\
\hline & & & DO & DOC & Ammonia & Nitrate & Sulfide & Sulfate & $\mathrm{Fe}_{\text {Tot }}$ & $\operatorname{As}(\mathrm{III})$ & $\operatorname{As}(\mathrm{V})$ & $\mathrm{As}_{\mathrm{Sum}}{ }^{\mathrm{a}}$ & & $\mathrm{Fe}_{\text {Tot }}$ & $\mathrm{As}_{\text {Tot }}{ }^{\mathrm{b}}$ & \\
\hline-1 & 93.6 & 8.09 & 0.36 & 3.43 & 9.44 & bdl & 156.25 & 236.14 & bdl & 3.45 & 4.88 & 8.33 & 0.59 & 543.90 & 87.97 & 0.28 \\
\hline 0 & 90.3 & 8.12 & 1.04 & 1.75 & 10.00 & bdl & 183.44 & 245.18 & bdl & 1.20 & 4.25 & 5.45 & 0.78 & 970.75 & 72.35 & 0.17 \\
\hline 4 & 68.6 & 8.46 & 0.61 & 2.01 & 3.33 & bdl & 35.94 & 256.08 & bdl & 9.89 & 3.84 & 13.73 & 0.28 & 29.39 & 84.37 & 2.02 \\
\hline 8 & 64.7 & 8.51 & 2.79 & 2.02 & 1.11 & 6.51 & 2.81 & 326.12 & bdl & 7.71 & 6.16 & 13.87 & 0.44 & 278.06 & 22.15 & 1.21 \\
\hline 12 & 49.6 & 8.87 & 3.30 & 0.80 & bdl & bdl & 0.31 & 363.97 & bdl & 7.26 & 6.59 & 13.86 & 0.48 & 268.40 & 67.51 & 2.60 \\
\hline
\end{tabular}

Table 1. Geochemistry of parallel water and sediment samples collected along the Zimeiquan outflow channel in Tengchong geothermal area. ${ }^{\mathrm{a}} \mathrm{As}_{\mathrm{Sum}}$ refers to the sum of $\mathrm{As}(\mathrm{III})$ and $\mathrm{As}(\mathrm{V}) .{ }^{\mathrm{b}} \mathrm{As}_{\mathrm{Tot}}$ refers to total As concentration extracted from sediments. bdl: below detection limit $(1 \mu \mathrm{g} / \mathrm{L})$.

alkaline Octopus Spring in Yellowstone National Park (YNP) was shown to utilize monothioarsenate to aerobically grow, with the final products being arsenate and sulfate ${ }^{17}$.

Previous studies found that the microbial population in the water and sediment of hot springs varied depending on the specific geochemistry of the site, even within the same pool ${ }^{18-20}$. Although As biogeochemistry has been studied in hot springs as described above, arsenic geochemistry and the corresponding microbial communities in these alkaline sulfide-rich hot springs is still poorly understood. For example, the relationship between water and sediment geochemistry and the extent microbial communities is still not clear, with the As biogeochemistry and related genes remaining unspecified. To address these unknowns, the current study examined a representative alkaline sulfide- and As-rich hot spring located in the Rehai geothermal field of Tengchong, China $^{21,22}$, and (1) systematically investigated the As geochemistry and microbial community structure in both water and sediments along the alkaline sulfide-rich hot spring outflow channel using Illumina MiSeq sequencing and clone libraries; (2) assessed the environmental factors shaping the microbial community structures; and (3) evaluated the potential microbially-mediated As transformation processes in the alkaline sulfide-rich hot spring.

\section{Results}

Water and sediment geochemistry. Characterized by high sulfide concentrations of 156.25$183.44 \mu \mathrm{mol} / \mathrm{L}$ ( or $5.00-5.87 \mathrm{mg} / \mathrm{L}$ ), the two adjacent pools of Zimeiquan had similar $\mathrm{pH}$ (8.09-8.12), temperature $\left(90.3-93.6^{\circ} \mathrm{C}\right)$ and ions concentrations (Table 1 and Supplementary Fig. S1). A higher dissolved oxygen (DO) concentration and $\mathrm{As}(\mathrm{V}) / \mathrm{As}_{\mathrm{Sum}}$ (the ratio between $\mathrm{As}(\mathrm{V})$ and the sum of $\mathrm{As}(\mathrm{III})$ and $\mathrm{As}(\mathrm{V})$ ) were measured in the right pool (site $0 \mathrm{~m}$ ) compared to left pool (site $-1 \mathrm{~m}$ ) (Table 1). Thioarsenic was detected in the pool water, with the major species being monothioarsenate $\left(\mathrm{H}_{3} \mathrm{AsSO}_{3}\right)$, dithioarsenate $\left(\mathrm{H}_{3} \mathrm{AsS}_{2} \mathrm{O}_{2}\right)$, and a low proportion of tetrathioarsenate $\left(\mathrm{H}_{3} \mathrm{AsS}_{4}\right)$. Once the source water discharged into the outflow channel, most of the physicochemical parameters changed dramatically (Fig. 1). Temperature ranged from $93.6^{\circ} \mathrm{C}$ to $49.6{ }^{\circ} \mathrm{C}$ along the outlet channel. The $\mathrm{pH}$ values slightly increased from 8.09 at $-1 \mathrm{~m}$ to 8.87 at $12 \mathrm{~m}$, which was primarily due to successive degassing (e.g. $\mathrm{CO}_{2}$ and $\left.\mathrm{H}_{2} \mathrm{~S}\right)^{23}$ and evaporation condensation ${ }^{24}$. DO, sulfate and $\mathrm{As}_{\mathrm{Sum}}$ concentrations increased from 0.36 to $3.30 \mathrm{mg} / \mathrm{L}, 236.14$ to $363.97 \mu \mathrm{mol} / \mathrm{L}$ and 5.45 to $13.86 \mu \mathrm{mol} / \mathrm{L}$ (or 0.62 to $1.11 \mathrm{mg} / \mathrm{L}$ ), respectively. Dissolved organic carbon (DOC), ammonia and sulfide concentrations declined from 3.43 to $0.80 \mathrm{mg} / \mathrm{L}, 10.00$ to $0 \mu \mathrm{mol} / \mathrm{L}$ and 156.25 to $0.31 \mu \mathrm{mol} / \mathrm{L}$, respectively. As(III) concentrations increased from $1.20 \mu \mathrm{mol} / \mathrm{L}$ at $0 \mathrm{~m}$ to $9.89 \mu \mathrm{mol} / \mathrm{L}$ at $4 \mathrm{~m}$ and then gradually declined to $7.26 \mu \mathrm{mol} / \mathrm{L}$ from $4 \mathrm{~m}$ to $12 \mathrm{~m}$. As $(\mathrm{V})$ concentrations were practically unchanged from $0 \mathrm{~m}$ to $4 \mathrm{~m}$, but increased from 3.84 to $6.59 \mu \mathrm{mol} / \mathrm{L}$ from $4 \mathrm{~m}$ to $12 \mathrm{~m}$ as did As(V)/As $s_{\text {Sum }}$ (0.28-0.48). Sediment $\mathrm{Fe}_{\mathrm{Tot}}$ and $\mathrm{As}_{\mathrm{Tot}}$ concentrations ranged from $29.39 \mathrm{mg} / \mathrm{kg}$ to $970.75 \mathrm{mg} / \mathrm{kg}$ and $22.15 \mathrm{mg} / \mathrm{kg}$ to $87.97 \mathrm{mg} / \mathrm{kg}$, respectively (Table 1 ). Total organic carbon (TOC) concentrations increased (1.21-2.60\%) in the downstream sediment samples.

Alpha diversity of microbial communities. A total of 256883 sequences were initially obtained from the five-paired parallel water and sediment samples. After rarefaction at 15000 sequences per sample, OTU clustering and removal of singletons, 148019 sequences remained. A variety of taxa were present, with 277-754 observed and 414-1167 predicted OTUs (based on Chao1) and coverage values ranging from $64.63 \%$ to $89.96 \%$ (Supplementary Table S1). Water samples had higher microbial community richness than sediment samples, whereas Shannon diversity and equitability were relatively lower, except for site $8 \mathrm{~m}$ (Fig. 2). It should be noted that though a distinct increase of community richness was observed from $-1 \mathrm{~m}$ to $4 \mathrm{~m}$, Shannon diversity and equitability of all samples did not generally present a significant change along the outflow channel. Additionally, no significant correlation could be found between diversity indices and environmental factors (data not shown).

Microbial community compositions and statistical analysis. Microbial community composition of the samples were distinctly different based on sample type (water vs. sediment) and by location (pools and downstream samples along the outflow channel) (Fig. 3). Water samples from the pools $(-1 \mathrm{~m}$ and $0 \mathrm{~m})$ were dominated by Aquificae (36.07-62.53\%), Proteobacteria (12.73-38.07\%), Crenarchaeota (7.21-11.68\%) and Thermodesulfobacteria (5.97-8.24\%). The parallel sediment samples also harbored the above phyla, but with significant different proportions: 47.67-71.89\% Proteobacteria, 19.78-25.01\% Crenarchaeota and 0-13.71\% Aquificae. After discharge along the outlet, downstream water samples (site $4 \mathrm{~m}, 8 \mathrm{~m}$, and $12 \mathrm{~m}$ ) harbored Aquificae (15.69-53.87\%), Proteobacteria (1.66-71.68\%), and Thermodesulfobacteria (1.60-11.21\%) as in the pool samples, but also diverse Deinococcus-Thermus (1.99-11.19\%), Bacteroidetes (1.13-5.51\%), Thermotogae 

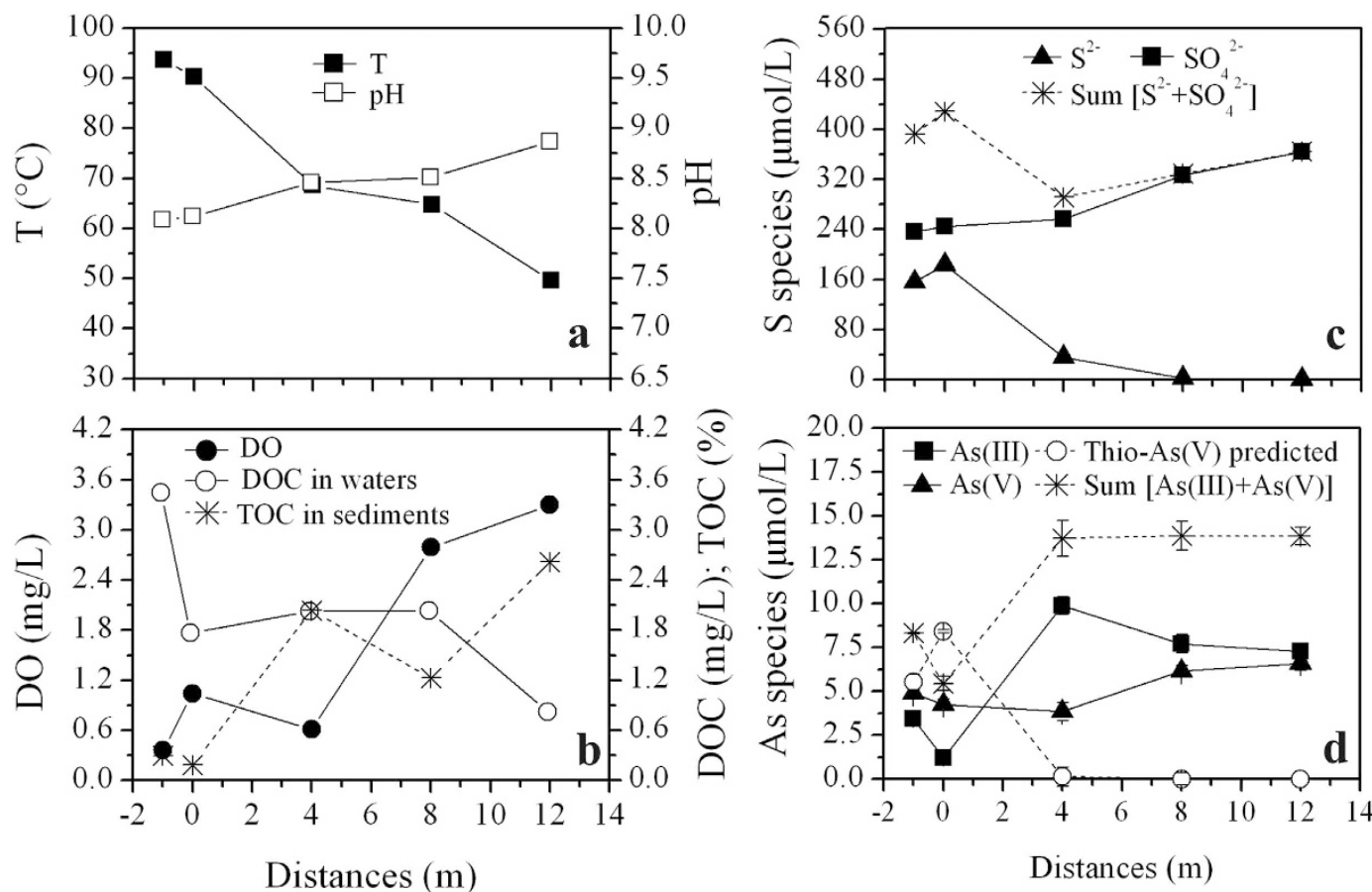

Figure 1. Distribution of selected geochemical data in water and sediment samples along the outflow channel of Zimeiquan. (a) T and pH; (b) DO and DOC in water samples and TOC in sediment samples; (c) sulfide and sulfate; (d) As(III), As(III), $\mathrm{As}_{\text {Sum }}$ and predicted thioarsenic. Error bars in Fig. 1d represent the standard deviations of duplicates.

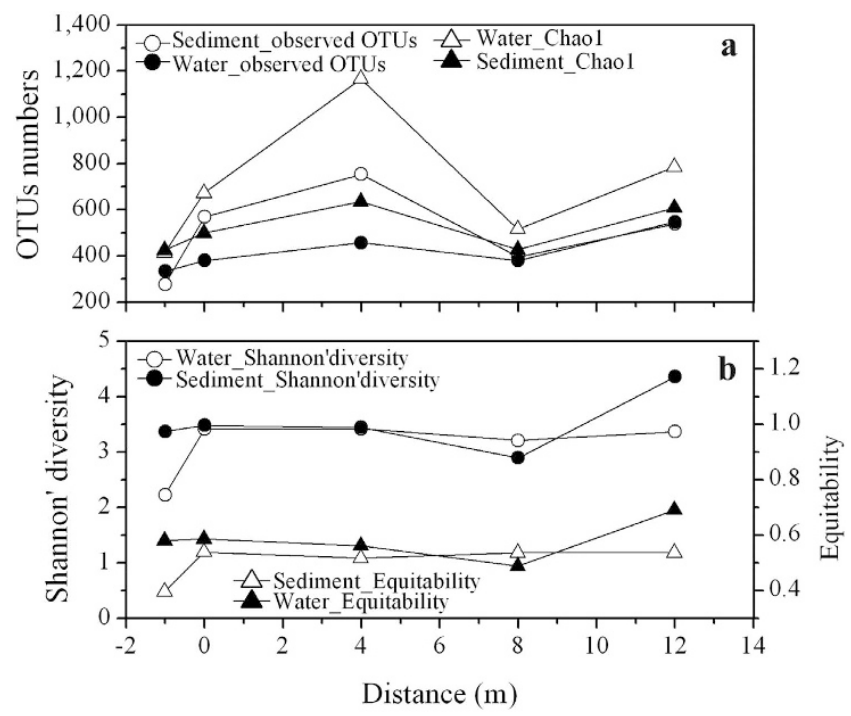

Figure 2. Alpha diversity indices distribution of microbial community structures of parallel samples collected along Zimeiquan outflow channel. (a) Observed OTUs numbers and Chao1. (b) Shannon' diversity and Equitability. The solid and open symbols refer to sediment and water samples respectively.

(0.12-4.46\%), and Chloroflexi $(0.27-2.24 \%)$. Downstream sediment samples were mainly dominated by Bacteroidetes (1.96-60.90\%), Chloroflexi (4.79-50.44\%), and Proteobacteria (2.16-15.55\%), with the remainder primarily composed of Armatimonadetes (1.38-6.16\%), Cyanobacteria (0.37-5.50\%), Deinococcus-Thermus (0.38-9.70\%) and Firmicutes (3.47-6.60\%). There were more unclassified phyla in the downstream sediment samples (11.19-40.71\%) than in the corresponding water samples (1.53-8.99\%).

At the genus level, samples from pools (site $-1 \mathrm{~m}$ and $0 \mathrm{~m}$ ) were mainly comprised of Thermocrinis (13.6861.97\%) of Aquificae, Ralstonia (1.87-17.96\%), Delftia (4.70-20.31\%), Undibacterium (1.32-8.10\%) and Acinetobacter (0.68-4.79\%) of Proteobacteria, Sulfophobococcus (1.25-17.42\%) and Pyrobaculum (0.08-7.96\%) of Crenarchaeota, and Caldimicrobium (5.97-8.24\%) of Thermodesulfobacteria (Fig. 4). Downstream water samples 


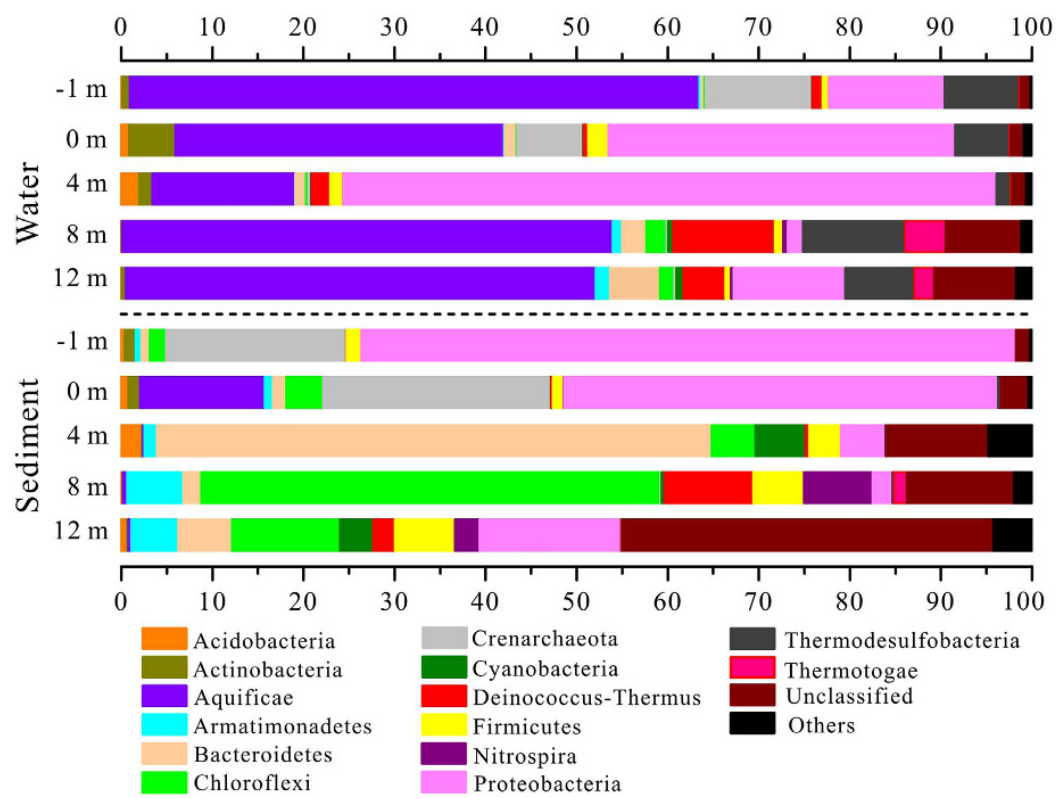

Figure 3. Microbial community structure of water and sediment samples along the Zimeiquan outflow channel at phylum level. Phyla with proportions higher than $4.5 \%$ are shown. Others named in the bar graph included phyla of Verrucomicrobia, Caldiserica, Chlamydiae, OD1, OP11, SR1, TM7, Chlorobi, Dictyoglomi, Euryarchaeota, Fibrobacteres, Gemmatimonadetes, Planctomycetes, and Spirochaetes.

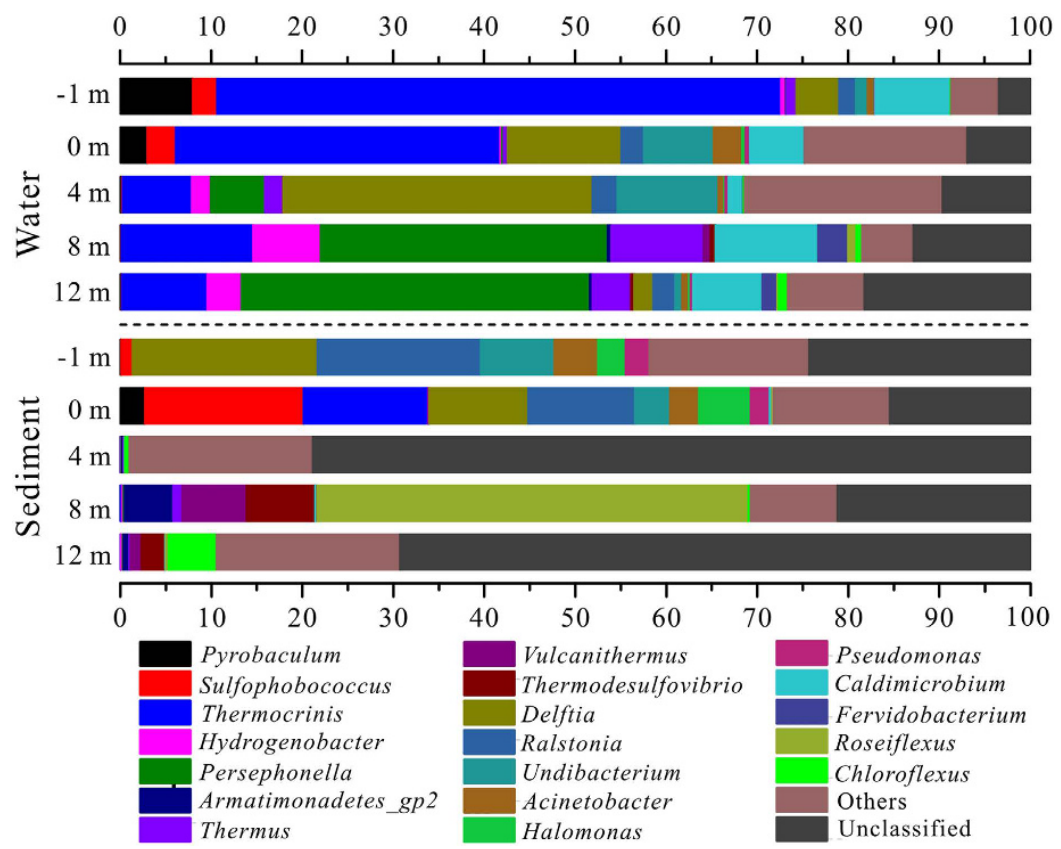

Figure 4. Microbial community structures of water and sediment samples along the Zimeiquan outflow channel at genus level. The ratios which exceeded $0.5 \%$ are displayed in the figure.

were mainly dominated by Persephonella (5.96-38.27\%), Thermocrinis (7.57-14.48\%) and Hydrogenobacter (2.11-7.41\%) of Aquificae, Thermus (1.97-10.15\%) of Deinococcus-Thermus and Caldimicrobium (1.58-11.20\%) of Thermodesulfobacteria. Comparatively, most of the sediment derived sequences at $4 \mathrm{~m}$ and $12 \mathrm{~m}$ could not be assigned to known genus (69.27-78.87\%). Only Roseiflexus (47.41\%) of Chloroflexi, Thermodesulfovibrio (7.54\%) of Nitrospira and Vulcanithermus (7.06\%) of Deinococcus-Thermus were the primary genera detected in the sediment sample at $8 \mathrm{~m}$.

Based on Bray-Curtis dissimilarity at a 97\% similarity level, the UPGMA cluster tree of the microbial community populations showed that sediment samples were distinctly separated from the water samples and were separated into two groups (pools and downstream) (Fig. 5a). Similar results were also observed with the PCoA 
$\mathbf{a}$

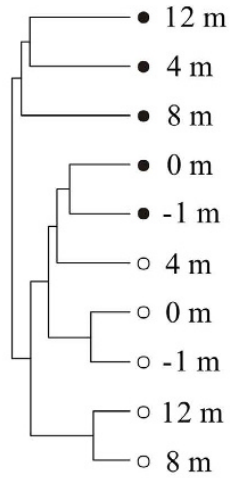

0.4

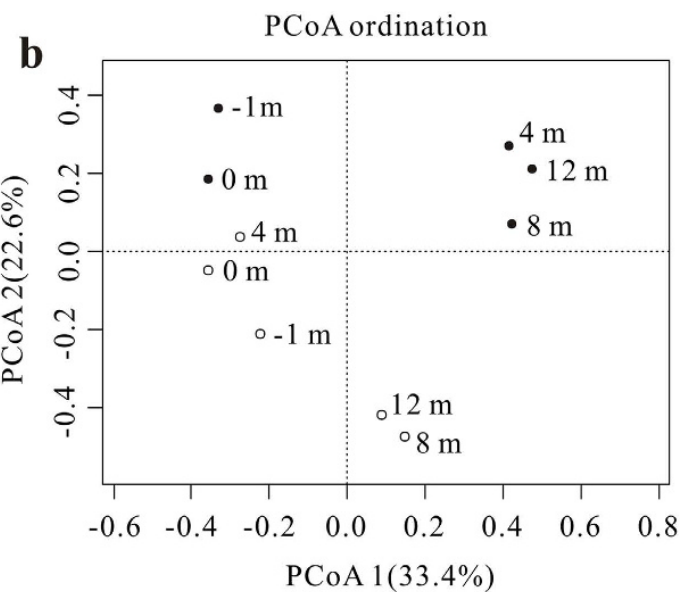

NMDS ordination

c

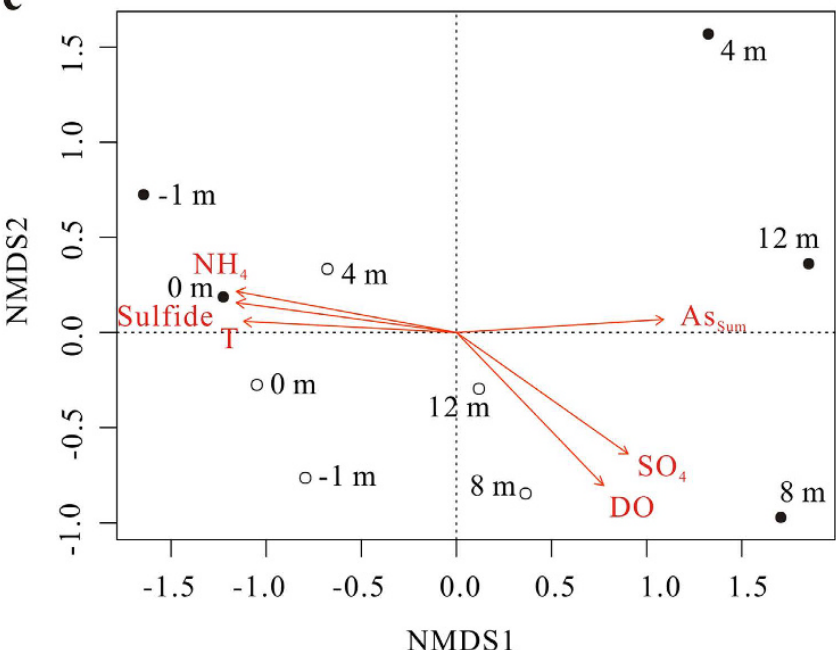

Figure 5. Microbial community distribution patterns at a $\mathbf{9 7 \%}$ similarity level. All analyses were performed based on Bray-Curtis dissimilarity of normalized OTU abundances of samples. The solid circles and open circles represented sediment and water samples respectively. (a) The hierarchical cluster tree using the unweighted pair group method with arithmetic means (UPGMA). (b) Principal coordinates analysis (PCoA) scatter plot. The first two factors, PCoA1 and PCoA2, explained $33.4 \%$ and $22.6 \%$ of the observed variation. (c) Non-metric multidimensional scaling (NMDS) ordination plot. A biplot was overlaid on the ordination to identify environmental factors that were correlated with microbial community structure. The length of the line corresponds to the degree of correlation. Only variables that had a significant correlation $(\mathrm{P}<0.05)$ are depicted.

analysis based on the Bray-Curtis dissimilarity matrix and explained 56\% of the observed variation (Fig. 5b). Consistent with these results, three complimentary non-parametric multivariate statistical tests including adonis, ANOISM, and MRPP revealed significant differences in microbial community structures not only between pools and the corresponding downstream samples, but also between water and sediment samples (Supplementary Table S2). Results of the Envfit function indicated that six geochemical parameters were significantly correlated $(\mathrm{P}<0.05)$ with microbial community structure of the outlet samples, including temperature, DO, ammonia, sulfide, sulfate, and $\mathrm{As}_{\text {Sum }}$ with $\mathrm{R}^{2}$ values of $0.61,0.61,0.67,0.66,0.60$ and 0.58 , respectively (Fig. $5 \mathrm{c}$ ). The similar direction of the ammonia, sulfide and temperature vectors, and the contrasting direction of the DO and sulfate vectors indicated correlations among these variables but did not necessarily suggest that all of the above environmental factors were responsible for the shift in the community structure.

As(III) oxidization and As(III) oxidase gene (aioA) diversity. Consistent with the observed As(III) oxidation downstream, enrichment products from the downstream sample at $8 \mathrm{~m}$ was found to exhibit a strong capacity for As(III) oxidization under chemolithoautotrophic conditions. The enrichment products completely oxidized $3 \mathrm{mM} \mathrm{As}$ (III) in $72 \mathrm{~h}$ at $65^{\circ} \mathrm{C}$ (Fig. 6). A total of 26 aio $A$ gene clone sequences from this enrichment products displayed a high similarity $(99 \%)$ and accordingly only one OTU was present in this library at a cutoff of 0.01 . All encoded aioA were closely related ( $>90 \%$ amino acid level) to that of Thermus in the phylum Deinococcus-Thermus (Supplementary Fig. S2). 


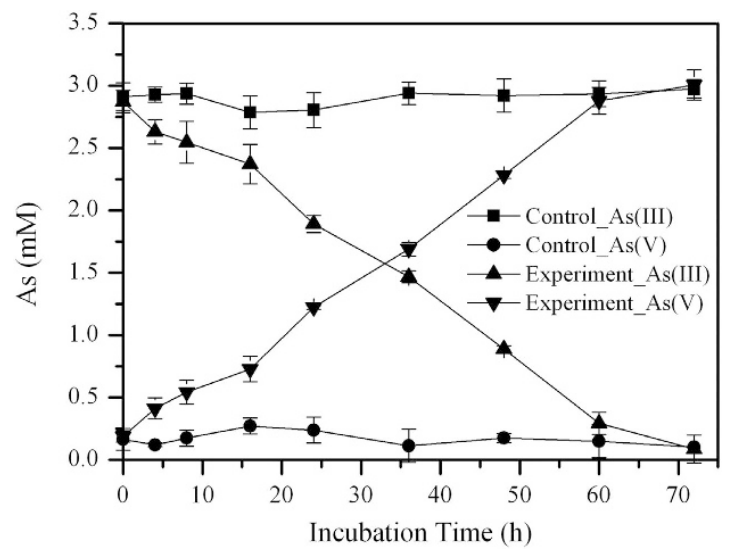

Figure 6. As(III) oxidation by enrichment product from Zimeiquan with minimal salt medium (MSM) containing $3 \mathrm{mM} \mathrm{As}(\mathrm{III})$. Experiments were carried out at $65^{\circ} \mathrm{C}$ under chemolithoautotrophic conditions. Abiotic controls were mock inoculated with sterile water. Error bars are the standard deviation of triplicate values.

\section{Discussion}

Sulfide can enhance microbial As(III) oxidation by stimulating the growth of indigenous sulfur-oxidizers in alkaline Mono Lake water'. The Zimeiquan pools are alkaline, sulfidic-rich, with As(V) as a dominant species. The high $\mathrm{As}(\mathrm{V}) / \mathrm{As}_{\text {Sum }}$ observed at this site suggests that $\mathrm{As}(\mathrm{III})$ oxidation occurred in these pools. This is a significant difference from previously studied acidic hot springs where microbial As(III) oxidation is potently inhibited by high sulfide concentration ${ }^{8,25}$, and highlights the distinct role of sulfide in As(III) oxidation in acidic and alkaline hot springs.

$\mathrm{As}_{\text {Sum }}$ significantly increased along the outflow channel. This might be due to evaporation condensation, dissolution from minerals, or transformation from thioarsenic. The lack of distinct change in representative ion concentrations (e.g., F, Cl, K and Na) along the outlet (Supplementary Fig. S1), and the slight fluctuation of As concentrations between sediments (Table 1) implies that As accumulation from evaporation condensation and mineral dissolution is negligible. Increased As(III) concentrations from $0 \mathrm{~m}$ to $4 \mathrm{~m}$ and subsequent decreases in concentration with a corresponding increase in $\mathrm{As}(\mathrm{V})$ from oxidation after $4 \mathrm{~m}$ (Fig. 1) suggest that the thioarsenate at this site is first converted to As(III) and then oxidized to As(V) after the thioarsenate disappears, as observed in previous studies ${ }^{12-14,16,26}$. Further, the reduced sulfur generated from the thioarsenate transformation was oxidized to sulfate as DO increased after $4 \mathrm{~m}$, which led to the increase of $S_{\text {sum }}$ from $4 \mathrm{~m}$ to $12 \mathrm{~m}(\text { Fig. } 1)^{16}$. Based on the As equilibrium observed in the three downstream sampling sites and the detection of monothioarsenate $\left(\mathrm{H}_{3} \mathrm{AsSO}_{3}\right)$, dithioarsenate $\left(\mathrm{H}_{3} \mathrm{AsS}_{2} \mathrm{O}_{2}\right)$ and tetrathioarsenate $\left(\mathrm{H}_{3} \mathrm{AsS}_{4}\right)$ in the pools, we calculated that thioarsenate concentrations in the pools should be 5.5-8.4 $\mu \mathrm{mol} / \mathrm{L}$ (Fig. 1d), and accounted for 39.9-60.7\% of the total As. This predicted proportion of thioarsenate is consistent with the previously observed range of 31.2-89.0\% in $\mathrm{YNP}^{14}$. These results implied that the increased As along the outflow channel is transformed from thioarsenate to As(III) and then oxidized to As(V).

Sequences with high similarity to the genus Thermocrinis, which are capable of mediating thioarsenic transformation, were dominant in our samples from $-1 \mathrm{~m}$ to $4 \mathrm{~m}$ (Fig. 7) and played a role in transformaing of the thioarsenate to As(III) along the outflow channel. Previous studies showed that the transformation from thioarsenate to As(III) observed in alkaline sulfidic-rich Conch and Ojo Caliente springs in YNP were mediated by Thermocrinis-dominant microbial mats ${ }^{13,14}$. Furthermore, Thermocrinis ruber OC 14/7/2 isolated from Octopus Spring was found to be capable of using monothioarsenate as a sole electron donor for growth and then converting it to $\mathrm{As}(\mathrm{III})$ and $\mathrm{As}(\mathrm{V})^{17}$. In contrast, the $\mathrm{As}(\mathrm{III})$ oxidation observed downstream was attributed to the significant appearance of Thermus (Fig. 7). Evidence of microbially-mediated As(III) oxidation downstream was found with the enrichments and can be reasonably linked to Thermus, which was a well-known As(III) oxidizer

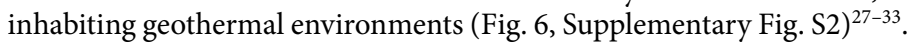

In addition to As, temperature, sulfide and DO were important environmental factors for determining the microbial community structure of the pools and downstream samples (Fig. 5). Due to the extremely high temperature, relatively low DO and high sulfide concentrations, the source waters from the pools were colonized by microaerophilic/anaerobic hyperthermophiles, such as Thermocrinis ${ }^{34}$, Caldimicrobium ${ }^{35}$, Sulfophobococcus ${ }^{36}$ and Pyrobaculum $^{37}$ (Figs 5 and 7). The dominant Thermocrinis and Caldimicrobium in the pools are representative sulfur oxidizers, which are widely distributed in other alkaline sulfidic-rich hot springs around the world ${ }^{15,38}$. Along the outflow channel, where the temperature rapidly decreased, some microaerophilic thermophilic populations including Ralstonia, Delftia and Undibacterium of Betaproteobacteria were detected in high abundance in downstream samples with relatively high DO (Fig. 7 and Table 1$)^{39}$. The shift from the sulfur oxidizer Thermocrinis in the source water to the thermophilic aerobic/microaerophilic Persephonella, Hydrogenobacter and Thermus downstream (Fig. 7), highlights the significant roles of temperature and DO in shaping the microbial community structure at this site $\mathrm{e}^{1,40,41}$. In the sediment samples, Proteobacteria and Crenarchaeota dominated in the pools and 

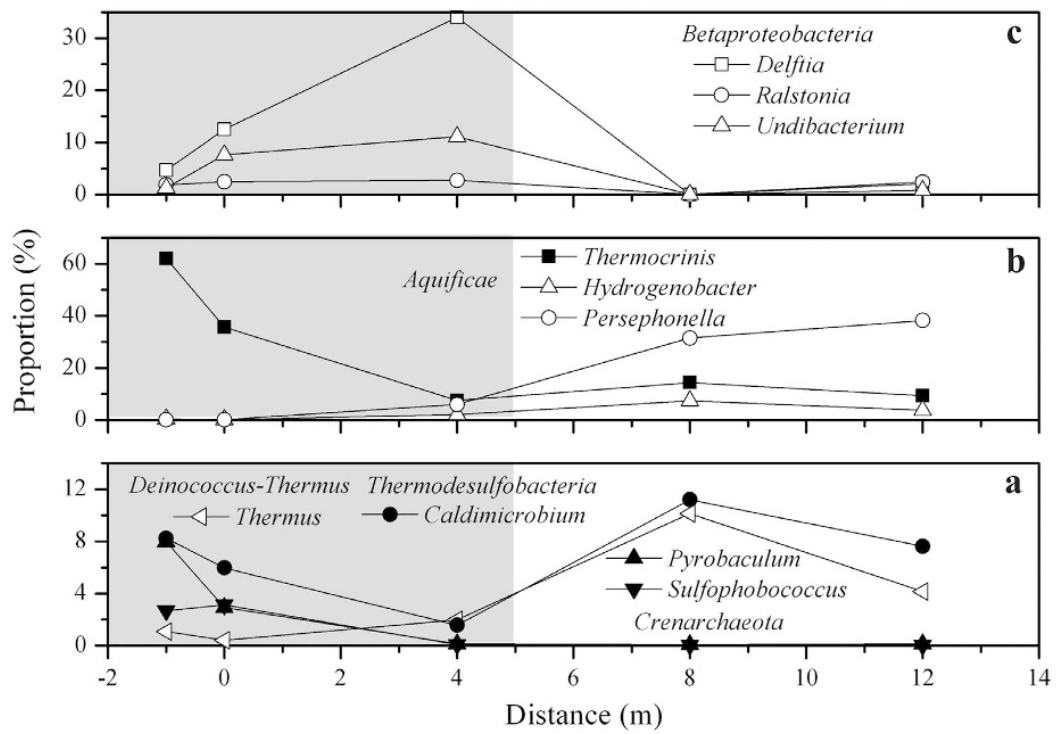

Figure 7. Distribution of dominant genera in water samples along the Zimeiquan outflow channel. (a) Pyrobaculum and Sulfophobococcus of Crenarchaeota, Thermus of Deinococcus-Thermus and Caldimicrobium of Thermodesulfobacteria; (b) Thermocrinis, Hydrogenobacter and Persephonella of Aquificae; (c) Delftia, Ralstonia and Undibacterium of Betaproteobacteria. Upstream sampling sites with relatively low DO concentrations $(0.36-1.04 \mathrm{mg} / \mathrm{L})$ are displayed in shadow.

some thermophilic photosynthetic bacteria, such as Roseiflexus and Chloroflexus of Chloroflexi, were predominant downstream (Figs 3 and 5), which is closer to their optimal growth temperature $\left(<70^{\circ} \mathrm{C}\right)^{42,43}$.

\section{Conclusions}

High ratios of $\mathrm{As}(\mathrm{V}) / \mathrm{As}_{\text {Sum }}$ suggested $\mathrm{As}(\mathrm{III})$ oxidation occurred in the alkaline sulfide-rich Zimeiquan pool. $\mathrm{As}_{\mathrm{Sum}}$ and total combined sulfide and sulfate concentrations substantially increased along the outflow channel, which implied the elevated As concentration was due to thioarsenic transformation. Temperature, sulfide, As and DO significantly influenced the microbial communities between not only the pools and downstream samples, but also water and sediment samples. In the upstream outflow channel, the dominant Thermocrinis transformed the thioarsenic to As(III), and then the downstream Thermus oxidized the derived As(III).

\section{Methods}

Site description. Zimeiquan (N24.95102 ${ }^{\circ}$, E98.43613 $)$, a representative alkaline sulfide-rich hot spring in the Rehai geothermal field of Tengchong, in Yunnan, southwestern China, was selected for this study (Supplementary Fig. S3). It has a pH of 9.0 , sulfide concentrations up to $4.8 \mathrm{mg} / \mathrm{L}^{22}$, and As concentrations up to $655.6 \mu \mathrm{g} / \mathrm{L}^{21}$. Zimeiquan is comprised of two adjacent pools, with a depth of $4.5-9.5 \mathrm{~cm}$ and a length of $8.5-1.0 \mathrm{~m}$. Spring water from the left pool flows into the right pool and then both are discharged along an outflow channel. Zimeiquan have a low water flow of 0.2-0.3 L/S. A transect of five sampling sites was established along the outlet. Sample identification was based on the relative distance in meters from the initial discharge point in the right pool (designated $0 \mathrm{~m}$ ). The left pool was designated $-1 \mathrm{~m}$, and the downstream outlet samples were $4 \mathrm{~m}, 8 \mathrm{~m}$ and $12 \mathrm{~m}$ (Supplementary Fig. S3). Parallel water and sediment samples at each sampling site were collected in August, 2014.

Field measurements and sample collection. Water temperature, $\mathrm{pH}$ and DO were measured in the field at the site of water collection using a hand-held meter. Concentrations of sulfide, ammonium, ferrous iron (Fe(II)) and total iron $\left(\mathrm{Fe}_{\mathrm{Tot}}\right)$ in the water were also determined in the field with a Hach spectrophotometer (DR850, Hach Corp., USA) according to the manufacturer's instructions. Approximately $250 \mathrm{~mL}$ water samples were collected for laboratory measurements using disposable $50 \mathrm{~mL}$ syringes and filtered through a $0.22 \mu \mathrm{m}$ polyethersulfone membrane syringe filters (to collect biomass) (Pall Corp., NY, USA) into $50 \mathrm{~mL}$ acid-washed polypropylene bottles (to measure anions and cations) and brown glass bottles (to measure thioarsenic and DOC). Water samples to be used for cations and DOC measurement were acidified with $1 \% \mathrm{v} / \mathrm{v} \mathrm{HNO}_{3}$. The filters were placed into $15 \mathrm{~mL}$ sterile polypropylene tubes for later DNA extraction. Separation of As species was done in situ, following Le et al. ${ }^{44}$. Briefly, $10 \mathrm{~mL}$ of each water sample was applied to a silica-based strong anion-exchange cartridge (Supelco, USA) preconditioned with 50\% methanol and deionized water before use. As(V) was retained in the cartridge and As(III) remained in the filtered solution. The As(V) was then eluted with $10 \mathrm{~mL} 1 \mathrm{~mol} \mathrm{HCl}$. Duplicate sediment samples were collected from each site using sterile spoons and transferred to sterile $50 \mathrm{~mL}$ polypropylene tubes that were immediately either stored on ice (for As-oxidizing microorganism isolation) or dry ice (for DNA extraction). All geochemical and DNA extraction samples were stored on dry ice in the field and during transportation, and then stored at $-80^{\circ} \mathrm{C}$ until analyzed. 
Laboratory geochemical analysis. Cation and anion concentrations were measured by inductively coupled plasma-optical emission spectrometry (CAP6300, Thermo, USA) and ion chromatography (ICS1100, Dionex, USA), respectively. Arsenic concentrations were determined using liquid chromatography-hydride generation-atomic fluorescence spectrometry (LC-HG-AFS, Haiguang AFS-9780, Beijing) ${ }^{33}$. Thioarsenic species were identified using Q Exactive, a high resolution quadrupole orbitrap mass spectrometer (Thermo Scientific, Germany), by detecting the accurate mass and matching the isotope abundance. DOC of water samples were determined using a TOC analyzer (TOC- $\mathrm{V}_{\mathrm{CPH}}$, Shimadzu, Japan). As and Fe in the sediments were extracted by 1:1 aqua regia digestion in a water bath ${ }^{45}$. Extracted Fe from sediments was determined by a 1,10-Phenanthroline-based assay: $10 \mathrm{~mL}$ extracted solutions were mixed with $5 \mathrm{~mL}$ acetate-sodium acetate buffer $(\mathrm{pH}=4.6), 2.5 \mathrm{~mL} 1 \%$ hydroxylamine hydrochloride and $5 \mathrm{~mL} 0.1 \% 1,10$-phenanthroline solution in a $50 \mathrm{~mL}$ volumetric flask. The mixture was brought up to a volume of $50 \mathrm{~mL}$ with deionized water and allowed to stand for $10 \mathrm{~min}$. The absorbance of each solution at $510 \mathrm{~nm}$ was measured with a spectrophotometer (UV1750, Shimadzu, Japan). TOC of sediment samples was measured with a Macro elemental analyzer (Multi EA 4000, Analytik Jena, Germany) after inorganic carbon was digested using $\mathrm{HCl}$.

As(III) oxidization experiments. Minimal salt medium (MSM) was used for enrichment of As(III)-oxidizer and assays for the detection of As oxidization under chemolithoautotrophic conditions. MSM contained (g/L): $\mathrm{Na}_{2} \mathrm{SO}_{4}, 0.031 ; \mathrm{KH}_{2} \mathrm{PO}_{4}, 0.17 ; \mathrm{KCl}, 0.15 ; \mathrm{MgCl}_{2} \cdot 6 \mathrm{H}_{2} \mathrm{O}, 0.04 ; \mathrm{CaCl}_{2} \cdot 2 \mathrm{H}_{2} \mathrm{O}, 0.05 ;\left(\mathrm{NH}_{4}\right)_{2} \mathrm{SO}_{4}, 0.4$; $\mathrm{NaHCO}_{3}, 1.68$; trace elements, $5 \mathrm{~mL}$ and vitamins solution, $10 \mathrm{~mL}^{5}$. The $\mathrm{pH}$ of the medium was adjusted to 8.5 to match that of Zimeiquan. About $2.5 \mathrm{~mL}$ of a water-sediment slurry at $8 \mathrm{~m}$ were inoculated in $50 \mathrm{~mL}$ MSM containing $3 \mathrm{mM} \mathrm{NaAsO}_{2}$. After one week incubation at $65^{\circ} \mathrm{C}, \sim 25 \mathrm{~mL}$ of the culture was centrifuged for $5 \mathrm{~min}$ at $4000 \mathrm{rpm}$ to collect biomass. The biomass was re-suspended in sterile water, and then inoculated in fresh MSM amended with $3 \mathrm{mM} \mathrm{NaAsO}$. An abiotic control was set up by adding sterile water to medium. Samples were taken periodically for As speciation. Experiments were run in triplicate.

DNA extraction, amplification and sequencing. DNA was extracted from filters or from $0.5 \mathrm{~g}$ sediment samples or from enrichment product using the FastDNA SPIN Kit for Soil (MP Biomedical, OH, USA). DNA concentrations were measured by Pico Green using a FLUOstar OPTIMA fluorescence plate reader (BMG LABTECH, Jena, Germany). The V4 region of the $16 \mathrm{~S}$ rRNA gene was amplified from DNA samples using the primer pair 515F (5'-GTGCCAGCMGCCGCGGTAA-3') and 806R (5'-GGACTACHVGGGTWTCTAAT-3') combined with Illumina adapter sequences, a pad and a linker of two bases, as well as barcodes on the reverse primers $^{46}$. PCR amplification was carried out in a $25 \mu \mathrm{L}$ reaction buffer containing $2.5 \mu \mathrm{L} 10 \times$ PCR buffer II (including dNTPs) (Invitrogen, Grand Island, NY), $0.4 \mu \mathrm{mol}$ of both forward and reverse primers, 10-15 ng DNA and $0.25 \mathrm{U}$ high fidelity AccuPrime ${ }^{\mathrm{TM}}$ Taq DNA polymerase (Life Technologies) using the following program: initial denaturation at $94^{\circ} \mathrm{C}$ for $1 \mathrm{~min}$, followed by 30 cycles of $94^{\circ} \mathrm{C}$ for $20 \mathrm{~s}, 53^{\circ} \mathrm{C}$ for $25 \mathrm{~s}$, and $68^{\circ} \mathrm{C}$ for $45 \mathrm{~s}$, and then a final extension at $68^{\circ} \mathrm{C}$ for $10 \mathrm{~min}$. Reactions were performed in triplicate and pooled. Positive PCR products were confirmed by agarose gel electrophoresis, then quantified with PicoGreen. Finally, $200 \mathrm{ng}$ of PCR product from each sample were combined together and purified using a QIAquick Gel Extraction Kit (Qiagen, Valencia, CA) and then re-quantified with PicoGreen. Sample libraries for sequencing were prepared according to the MiSeqTM Reagent Kit Preparation Guide (Illumina, San Diego, CA, USA) ${ }^{47}$. Briefly, sample denaturation was performed by mixing $10 \mu \mathrm{L}$ of combined PCR products $(2 \mathrm{nmol})$ and $10 \mu \mathrm{L} 0.2 \mathrm{~mol} \mathrm{NaOH}$ and incubated for $8 \mathrm{~min}$ at room temperature. Denatured DNA was diluted to $15 \mathrm{pM}$ using HT1 buffer and mixed with a PhiX DNA library (final concentration 14.3\%). A total of $600 \mu \mathrm{L}$ sample mixture, together with customized sequencing primers for forward, reverse, and index reads, were loaded into the corresponding wells on the reagent cartridge of a 500-cycle v2 MiSeq kit and run on an Illumina MiSeq system (Illumina, San Diego, CA).

The aioA genes were amplified from DNA extracted from the enrichments using degenerate primers aioA95f (TGYCABTWCTGCAIYGYIGG) and aioA599r (TCDGARTTGTASGCIGGICKRTT) in a $25 \mu L$ PCR mixture consisting of PCR Ex Taq buffer, $100 \mu \mathrm{mol}$ dNTP mixtures, $0.5 \mu$ mol primers, $50 \mathrm{ng}$ templates and $1 \mathrm{U}$ of Ex Taq DNA polymerase (TaKaRa, Japan $)^{27}$. The PCR program was as follows: initial denaturation at $94^{\circ} \mathrm{C}$ for 5 min, followed by 9 cycles of denaturation at $94^{\circ} \mathrm{C}$ for $45 \mathrm{~s}$, annealing at $54^{\circ} \mathrm{C} \mathrm{C} \mathrm{for} 45 \mathrm{~s}$, extension at $72^{\circ} \mathrm{C} \mathrm{for} 1.5 \mathrm{~min}$, and 25 cycles of denaturation at $94^{\circ} \mathrm{C}$ for $45 \mathrm{~s}$, annealing at $50^{\circ} \mathrm{C}$ for $45 \mathrm{~s}$, extension at $72^{\circ} \mathrm{C}$ for $1.5 \mathrm{~min}$, and then a final extension step at $72^{\circ} \mathrm{C}$ for $7 \mathrm{~min}^{27}$. PCR product was purified using the E.Z.N.A. Gel Extraction Kit (Omega Bio-tek, Inc. GA, USA). The purified PCR product was ligated into pMD-18T vectors (TaKaRa) and transformed into Escherichia coli DH5a competent cells. The transformed cells were plated on Luria-Bertani (LB) plates containing $100 \mu \mathrm{g} / \mathrm{mL}$ of ampicillin, $80 \mu \mathrm{g} / \mathrm{mL}$ of 5-bromo-4-chloro-3-indolyl-b-D-galactopyranoside (X-Gal) and $0.5 \mathrm{mmol}$ isopropyl-b-D-thiogalactopyranoside (IPTG), and incubated overnight at $37^{\circ} \mathrm{C}$. Twenty-six randomly chosen white colonies were sequenced with an ABI 3730 automated sequencer.

Sequence data preprocessing and statistical analysis. Raw $16 \mathrm{~S}$ rRNA sequences with perfect matches to barcodes were split to sample libraries and were trimmed using Btrim with a QC threshold of greater than 25 over a $5 \mathrm{bp}$ window size and a minimum length of $150 \mathrm{bp}^{48}$. Forward and reverse reads with at least $50 \mathrm{bp}$ overlap and less than 5\% mismatches were joined using Fast Length Adjustment of SHort reads (FLASH) ${ }^{49}$. After trimming of ambiguous bases (i.e. N), joined sequences with lengths between 247 and 258 bp were subjected to chimera removal by $U_{c h i m e}{ }^{50}$. Clustering of operational taxonomic units (OTUs) was performed by Uclust at a similarity level of $97 \%{ }^{51}$, and taxonomic assignment was through the Ribosomal Database Project (RDP) classifier with a minimal $50 \%$ confidence estimate ${ }^{52}$. Samples were rarefied at 15000 sequences per sample. Singletons in generated OTU tables were removed for downstream analyses. The above steps were performed through a Galaxy-based pipeline at the Institute for Environmental Genomics, University of Oklahoma (http://zhoulab5. rccc.ou.edu/). All statistical analyses in this study were performed based on genus-level OTUs at a $97 \%$ similarity 
level with the Vegan package in R (http://www.r-project.org/), unless otherwise stated. A variety of alpha diversity indices were calculated including Chao1, Shannon and Equitability. Hierarchical clustering trees using the unweighted pair group method with arithmetic means (UPGMA), principal coordinates analysis (PCoA) and non-metric dimensional scaling (NMDS) ordination plots were built to depict the community structure based on the the Bray-Curtis dissimilarity matrix of detected OTUs. The Envfit function in the Vegan package was used to overlay significant environmental variables on the NMDS ordination. Analyses of similarity (ANOSIM), non-parametric multivariate ANOVA (ADONIS) and multi-response permutation procedure (MRPP) were performed to test for significant differences of microbial community composition between sample types (i.e., water vs. sediment) and different locations (i.e., springs vs. downstream). DNA sequences were deposited to the Short Read Archive database at NCBI (Accession number: SRP059839).

The aio $A$ gene nucleotide sequences were edited in MEGA 5.05 and binned into various operational taxonomic units (OTU) using DOTUR 1.53. A representative sequence from the one OTU (0.01 cutoff) identified was selected for phylogenetic analysis. Prior to phylogenetic analysis, the representative aio $A$ gene sequence was translated into amino acid sequences and compared with closely related AioA amino acid sequences in the GenBank database (BLASTX), which were then used to construct a phylogenetic tree with MEGA 5.05. The aio $A$ gene fragment nucleotide sequences were deposited in the GenBank database under accession number KU311042.

\section{References}

1. Kozubal, M. A. et al. Geoarchaeota: a new candidate phylum in the Archaea from high-temperature acidic iron mats in Yellowstone National Park. ISME J 7, 622-634 (2013).

2. Beam, J. P., Jay, Z. J., Kozubal, M. A. \& Inskeep, W. P. Niche specialization of novel Thaumarchaeota to oxic and hypoxic acidic geothermal springs of Yellowstone National Park. ISME J 8, 938-951 (2014).

3. Li, S.-J. et al. Microbial communities evolve faster in extreme environments. Sci Rep 4, 6205 (2014)

4. Hedlund, B. P. et al. Isolation of diverse members of the Aquificales from geothermal springs in Tengchong, China. Front Microbiol 6, 157 (2015)

5. Jiang, D. et al. Chemolithoautotrophic arsenite oxidation by a thermophilic Anoxybacillus flavithermus strain TCC9-4 from a hot spring in Tengchong of Yunnan, China. Front Microbiol 6, 360 (2015).

6. Jackson, C. R., Langner, H. W., Donahoe-Christiansen, J., Inskeep, W. P. \& McDermott, T. R. Molecular analysis of microbial community structure in an arsenite-oxidizing acidic thermal spring. Environ Microbiol 3, 532-542 (2001).

7. Clingenpeel, S. R., D'Imperio, S., Oduro, H., Druschel, G. K. \& McDermott, T. R. Cloning and in situ expression studies of the Hydrogenobaculum arsenite oxidase genes. Appl Environ Microbiol 75, 3362-3365 (2009).

8. D’Imperio, S., Lehr, C. R., Breary, M. \& McDermott, T. R. Autecology of an arsenite chemolithotroph: sulfide constraints on function and distribution in a geothermal spring. Appl Environ Microbiol 73, 7067-7074 (2007).

9. Fisher, J. C., Wallschlager, D., Planer-Friedrich, B. \& Hollibaugh, J. T. A new role for sulfur in arsenic cycling. Environ Sci Technol 42, 81-85 (2008).

10. Planer-Friedrich, B., London, J., McCleskey, R. B., Nordstrom, D. K. \& Wallschlaeger, D. Thioarsenates in geothermal waters of yellowstone national park: Determination, preservation, and geochemical importance. Environ Sci Technol 41, 5245-5251 (2007).

11. Keller, N. S., Stefánsson, A. \& Sigfússon, B. Arsenic speciation in natural sulfidic geothermal waters. Geochim Cosmochim Ac 142, 15-26 (2014)

12. Planer-Friedrich, B., London, J., McCleskey, R. B., Nordstrom, D. K. \& Wallschlaeger, D. Importance of thioarsenates for arsenic redox processes along geothermal drainages, Yellowstone National Park. Geochim Cosmochim Ac 71, A795-A795 (2007).

13. Hartig, C. \& Planer-Friedrich, B. Thioarsenate transformation by filamentous microbial mats thriving in an alkaline, sulfidic hot spring. Environ Sci Technol 46, 4348-4356 (2012).

14. Planer-Friedrich, B., Fisher, J. C., Hollibaugh, J. T., Suess, E. \& Wallschlaeger, D. Oxidative Transformation of trithioarsenate along alkaline geothermal drainages-abiotic versus microbially mediated processes. Geomicrobiol J 26, 339-350 (2009).

15. Inskeep, W. P. et al. The YNP metagenome project: environmental parameters responsible for microbial distribution in the Yellowstone geothermal ecosystem. Front Microbiol 4, 67 (2013).

16. Edwardson, C. F., Planer-Friedrich, B. \& Hollibaugh, J. T. Transformation of monothioarsenate by haloalkaliphilic, anoxygenic photosynthetic purple sulfur bacteria. FEMS Microbiol Ecol 90, 858-868 (2014).

17. Hartig, C. et al. Chemolithotrophic growth of the aerobic hyperthermophilic bacterium Thermocrinis ruber OC $14 / 7 / 2$ on monothioarsenate and arsenite. FEMS Microbiol Ecol 90, 747-760 (2014).

18. Cole, J. K. et al. Sediment microbial communities in Great Boiling Spring are controlled by temperature and distinct from water communities. ISME J 7, 718-729 (2013).

19. Hou, W. et al. A comprehensive census of microbial diversity in hot springs of Tengchong, Yunnan Province China using 16S rRNA gene pyrosequencing. Plos One 8, e53350 (2013).

20. Wang, S. et al. Greater temporal changes of sediment microbial community than its waterborne counterpart in Tengchong hot springs, Yunnan Province, China. Sci Rep 4, 7479 (2014).

21. Guo, Q. \& Wang, Y. Geochemistry of hot springs in the Tengchong hydrothermal areas, Southwestern China. J Volcanol Geoth Res 215, 61-73 (2012).

22. Jiang, H. et al. RNA-based investigation of ammonia-oxidizing archaea in hot springs of Yunnan Province, China. Appl Environ Microbiol 76, 4538-4541 (2010).

23. Planer-Friedrich, B. \& Wallschlaeger, D. A critical investigation of hydride generation-based arsenic speciation in sulfidic waters. Environ Sci Technol 43, 5007-5013 (2009).

24. Macur, R., Langner, H., Kocar, B. \& Inskeep, W. Linking geochemical processes with microbial community analysis: successional dynamics in an arsenic-rich, acid-sulphate-chloride geothermal spring. Geobiology 2, 163-177 (2004).

25. Donahoe-Christiansen, J., D’Imperio, S., Jackson, C. R., Inskeep, W. P. \& McDermott, T. R. Arsenite-oxidizing hydrogenobaculum strain isolated from an acid-sulfate-chloride geothermal spring in Yellowstone National Park. Appl Environ Microbiol 70, 1865-1868 (2004).

26. Planer-Friedrich, B. et al. Anaerobic chemolithotrophic growth of the haloalkaliphilic bacterium strain MLMS-1 by disproportionation of monothioarsenate. Environ Sci Technol 49, 6554-6563 (2015).

27. Hamamura, N. et al. Linking microbial oxidation of arsenic with detection and phylogenetic analysis of arsenite oxidase genes in diverse geothermal environments. Environ Microbiol 11, 421-431 (2009).

28. Cavalca, L., Corsini, A., Zaccheo, P., Andreoni, V. \& Muyzer, G. Microbial transformations of arsenic: perspectives for biological removal of arsenic from water. Future Microbiol 8, 753-768 (2013).

29. Gihring, T. M. \& Banfield, J. F. Arsenite oxidation and arsenate respiration by a new Thermus isolate. FEMS Microbiol Lett 204, 335-340 (2001) 
30. Gihring, T. M., Druschel, G. K., McCleskey, R. B., Hamers, R. J. \& Banfield, J. F. Rapid arsenite oxidation by Thermus aquaticus and Thermus thermophilus: Field and laboratory investigations. Environ Sci Technol 35, 3857-3862 (2001).

31. Hamamura, N., Macur, R. E., Liu, Y., Inskeep, W. P. \& Reysenbach, A. L. In Interdisciplinary studies on environmental chemistrybiological responses to contaminants (eds Hamamura, N. et al.) 47-55 (TERRAPUB, Tokyo, 2010).

32. Stolz, J. F., Basu, P. \& Oremland, R. S. Microbial arsenic metabolism: new twists on an old poison. Microbe 5, 53-59 (2010).

33. Jiang, Z. et al. Diversity and abundance of the arsenite oxidase gene aioA in geothermal areas of Tengchong, Yunnan, China. Extremophiles 18, 161-170 (2014).

34. Huber, R. et al. Thermocrinis ruber gen. nov., sp. nov., a pink-filament-forming hyperthermophilic bacterium isolated from Yellowstone National Park. Appl Environ Microbiol 64, 3576-3583 (1998).

35. Miroshnichenko, M. L. et al. Caldimicrobium rimae gen. nov., sp. nov., an extremely thermophilic, facultatively lithoautotrophic, anaerobic bacterium from the Uzon Caldera, Kamchatka. Int J Syst Evol Microbiol. 59, 1040-1044 (2009).

36. Hensel, R. et al. Sulfophobococcus zilligii gen. nov., spec. nov. a novel hyperthermophilic archaeum isolated from hot alkaline springs of Iceland. Syst Appl microbiol 20, 102-110 (1997).

37. Völkl, P. et al. Pyrobaculum aerophilum sp. nov., a novel nitrate-reducing hyperthermophilic archaeum. Appl Environ Microbiol 59, 2918-2926 (1993).

38. Meyer-Dombard, D. R. et al. Hydrothermal ecotones and streamer biofilm communities in the Lower Geyser Basin, Yellowstone National Park. Environ Microbiol 13, 2216-2231 (2011).

39. Aminin, A. L. N., Warganegara, F. M. \& Aditiawati, P. Culture-independent and culture-dependent approaches on microbial community analysis at Gedongsongo (GS-2) hot spring. Int J Integ Biol 2, 145-152 (2008).

40. Wang, S. et al. Control of temperature on microbial community structure in hot springs of the Tibetan Plateau. Plos One 8, e62901 (2013).

41. Briggs, B. R. et al. Seasonal patterns in microbial communities inhabiting the hot springs of Tengchong, Yunnan Province, China. Environ Microbiol 16, 1579-1591 (2014).

42. Hanada, S., Takaichi, S., Matsuura, K. \& Nakamura, K. Roseiflexus castenholzii gen. nov., sp. nov., a thermophilic, filamentous, photosynthetic bacterium that lacks chlorosomes. Int J Syst Evol Microbiol 52, 187-193 (2002).

43. Engel, A. S., Johnson, L. R. \& Porter, M. L. Arsenite oxidase gene diversity among Chloroflexi and Proteobacteria from El Tatio Geyser Field, Chile. FEMS Microbiol Ecol 83, 745-756 (2013).

44. Le, X. C., Yalcin, S. \& Ma, M. S. Speciation of submicrogram per liter levels of arsenic in water: On-site species separation integrated with sample collection. Environ Sci Technol 34, 2342-2347 (2000).

45. Deng, Y., Wang, Y., Ma, T., Yang, H. \& He, J. Arsenic associations in sediments from shallow aquifers of northwestern Hetao Basin, Inner Mongolia. Environ Earth Sci 64, 2001-2011 (2011)

46. Caporaso, J. G. et al. Global patterns of $16 \mathrm{~S}$ rRNA diversity at a depth of millions of sequences per sample. PNAS 108, 4516-4522 (2011).

47. Caporaso, J. G. et al. Ultra-high-throughput microbial community analysis on the Illumina HiSeq and MiSeq platforms. ISME J 6, $1621-1624$ (2012).

48. Kong, Y. Btrim: A fast, lightweight adapter and quality trimming program for next-generation sequencing technologies. Genomics 98, 152-153 (2011).

49. Magoc, T. \& Salzberg, S. L. FLASH: fast length adjustment of short reads to improve genome assemblies. Bioinformatics 27, 2957-2963 (2011).

50. Edgar, R. C., Haas, B. J., Clemente, J. C., Quince, C. \& Knight, R. UCHIME improves sensitivity and speed of chimera detection. Bioinformatics 27, 2194-2200 (2011).

51. Edgar, R. C. Search and clustering orders of magnitude faster than BLAST. Bioinformatics 26, 2460-2461 (2010).

52. Wang, Q., Garrity, G. M., Tiedje, J. M. \& Cole, J. R. Naive Bayesian classifier for rapid assignment of rRNA sequences into the new bacterial taxonomy. Appl Environ Microbiol 73, 5261-5267 (2007).

\section{Acknowledgements}

This research was financially supported by National Natural Science Foundation of China (Grant No. 41120124003, 41521001, 41372348), the Fundamental Research Funds for the Central Universities (No. CUG140505) and State Key Laboratory of Biogeology and Environmental Geology, China University of Geosciences (No. GBL11505).

\section{Author Contributions}

Z.J., P.L. and Y.W. (Yanxin Wang) conceived and designed the experiments. Z.J., P.L., Y.W. (Yanhong Wang), X.D., R.Z. and D.J. contributed to field sampling. Z.J., P.L. and P.Z. conducted the experiment. Z.J. wrote the first draft of the manuscript. P.L., J.D.V.N., J.Z. and Y.W. (Yanxin Wang) contributed to the revisions.

\section{Additional Information}

Supplementary information accompanies this paper at http://www.nature.com/srep

Competing financial interests: The authors declare no competing financial interests.

How to cite this article: Jiang, Z. et al. Microbial communities and arsenic biogeochemistry at the outflow of an alkaline sulfide-rich hot spring. Sci. Rep. 6, 25262; doi: 10.1038/srep25262 (2016).

This work is licensed under a Creative Commons Attribution 4.0 International License. The images or other third party material in this article are included in the article's Creative Commons license, unless indicated otherwise in the credit line; if the material is not included under the Creative Commons license, users will need to obtain permission from the license holder to reproduce the material. To view a copy of this license, visit http://creativecommons.org/licenses/by/4.0/ 